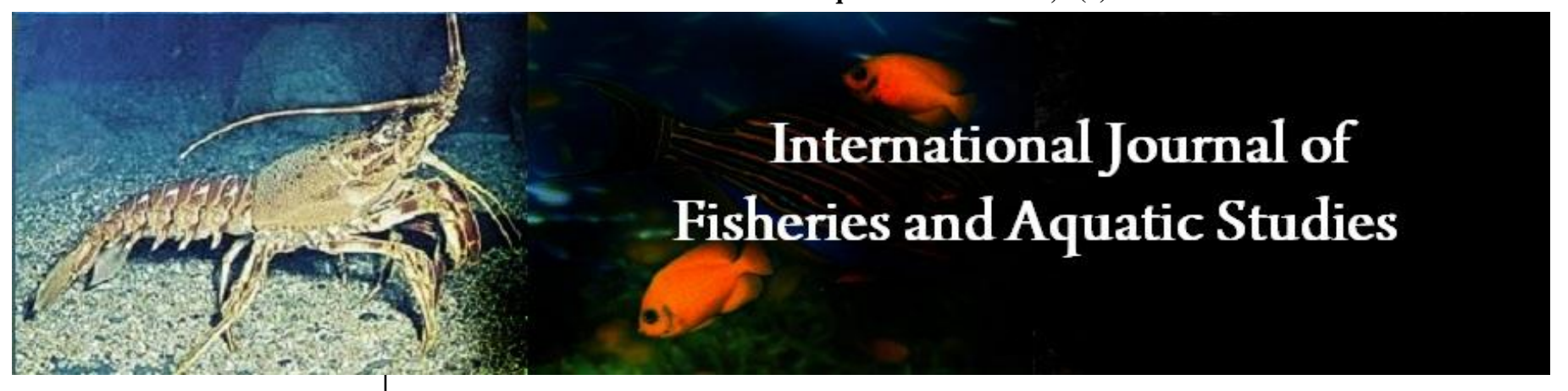

E-ISSN: 2347-5129

P-ISSN: 2394-0506

(ICV-Poland) Impact Value: 5.62

(GIF) Impact Factor: 0.549

IJFAS 2021; 9(5): 108-110

(C) 2021 IJFAS

www.fisheriesjournal.com

Received: 08-07-2021

Accepted: 27-08-2021

Ganga Prasad Thakur

Department of Zoology, LN

Mithila University, Darbhanga,

Bihar, India
Corresponding Author: Ganga Prasad Thakur Department of Zoology, LN Mithila University, Darbhanga, Bihar, India

\section{Intestinal Histopathologies due to infestation of Bothriocephalus acheilognathi in the common carp, Cyprinus carpio (Linn. 1758)}

\section{Ganga Prasad Thakur}

DOI: https://doi.org/10.22271/fish.2021.v9.i5b.2573

\begin{abstract}
The present investigation was undertaken to study the intestinal histopathologies due to infestation of helminth parasite, Bothriocephalus acheilognathi in the Cyprinus carpio. Only symptomatic and moribund samples of adult diseased fishes of Cyprinus carpio were collected and were brought to the laboratory for patho-morphological and patho-anatomical examinations. The main histopathological lesions and changes were seen in the intestine. The prominent cells were shrinking of nucleus indicating pyknosis gradual loss of parts and mucosal and submucosal cells, excessive mucus secretion and lymphatic infiltration in lamina propria. Further edema and extreme of necrosis as apparent from cells undergoing process death was another important pathology induced by B. acheilognathi. In addition to these findings, shorting atrophy and villi almost complete loss of normal architecture changes were found histopathological important in intestine of C. carpio. No changes were noticed in other organs of the affected fishes. In severe infestations the fishes showed growth retardation.
\end{abstract}

Keywords: Bothriocephalus acheilognathi, histopathology, cestode, intestine, symptom, Cyprinus carpio

\section{Introduction}

Helminths constitute one of the major and important group of parasites of fish and cause a severe loss in fish production (Jha, et al. 1992) ${ }^{[5]}$. Like other parasites, helminthes also take nutrition from their hosts thereby depriving them of required nutrients and growth retardation resulting into morbidity and mortality with consequent economic losses (Marcogliese, 2001) ${ }^{[8]}$. It is important to mention here that the parasitic infestations are reportedly playing a major role in disease occurrences $(78 \%)$ in Indian freshwater aquaculture. There are around $21 \%$ production loss due to diseases, poor farm management practices and impaired growth.

Fish play the most significant role as host in helminths life cycle. The helminth parasites induce pathological lesions or histological damages in tissues, thereby greatly reducing their nutritional value and become potential threat to human health due to consumption of such infected fishes (Camargo and Martinez, 2007) ${ }^{[2]}$. Histological changes are used as indicators of the health of oerall population in the ecosystem (Ramdu and Dash, 2015) ${ }^{[9]}$.

So the objective of the present study was to investigate the exerted profound effects on histology of intestine in common carp, Cyprinus carpio by cestode, the Asian fish tapeworm, Bothriocephalus acheilognathi (Yamaguti, 1934) ${ }^{[14]}$ infestation.

\section{Materials and Methods}

Frequent incidences of naturally occurring Bothriocephalus acheilognathi infestation was recorded in the cultivated ponds/tanks/rivers in Darbhanga, Bihar during the period of observation (2017-2019). Only juvenile and adults of common carp parasitized with $B$. acheilognathi were brought to the laboratory for Patho-anatomical examinations. After that small bits of tissues (3-4 mm thick) from the intestine etc. of moribund or freshly killed diseased fish (common carp) samples were collected and fixed in ten percent Neutral Buffered Formalin for 18-24 hours. Fixed tissue samples were then processed and paraffin embedded blocks of all the tissues were prepared using the standard histological methods (Luna, 1968) ${ }^{[6]}$. Calcified tissues like skin and gills were decalcified in ten percent Nitric Acid which helped in getting perfect and unbroken serial sections of these tissues during microtomy. 
Tissue blocks were cut into serial sections (5-7 thick) by a rotary microtome. For routine staining of the histological sections, Ehrlich's Haematoxylin (H.) and alcoholic Eosin (E.) stains were prepared and used according to Luna (1968) [6]. Photomicrographs of the most characteristic regions of histopathological lesions in the stained tissues of diseased fish samples were taken.

\section{Result}

This disease has been found to occur predominantly in the in the large fish culture ponds. The disease is caused by a cestode, parasite $B$. acheilognathi which attracted particularly the intestine of the fishes.

Fish Species affected: juvenile / adults of Cyprinus carpio,(Linn.1758) has been found to be affected by this disease.

Clinical Symptoms and Gross pathology: Highly affected fishes showed growth retardation, weight loss, lethargic swimming behaviour, loss of appetite and tendency to take shelter near pond margin. Histopathological examination of the intestine of Cyprinus carpio was infested parasitized $B$. acheilognathi. The parasite has a ribbon-like body measureing between 35.0 to $80.0 \mathrm{~mm}$ in length and 2.5 to $4.0 \mathrm{~mm}$ in width, inverted heart shaped scolex. Its body consists of flattened segments or proglottids.

\section{Histopathology}

The intestine of the normal $C$. carpio exhibited well ordered arrangement of the usual four layers i.e., serosa, muscularis, submucosa and mucosa (Figure-1). The outer most thin ascular covering is the serosa. The mucosa is formed of columnar epithelial cells thrown into a number of folds or villi.

Intestinal histopathology in $C$. carpio due to infestation of $B$. acheilognathi following alteration found, the intestinal cells were observed to have shrinking ncleus, a symptom of pyknosis and gradual loss of parts of the cells (mucosal as well as submucosal), edema, and extreme condition of necrosis denoting cells undergoing process of death (Figure2). Besides, excessive mucus secretion, lymphatic infiltration in bothrial laminapropia observed.

The parasites attachment to gut the host fish was observed to engulf the intestinal folds which compressed the mucosal epithelium, exerted localized pressure and induced necrosis and hemorrhage (Figure-3). The formation of pits were extending almost up to muscularis due to compression exerted by the bothria for firm attachment of scolex in gut wall also apparent and this also induced loss of brush border (Figure-4). Again thinning of the intestine at the point of attachment of the parasite was also obvious.

Diagnostic histopathological lesions identified: The intestine was greatly obstructed and weakened due to infestation of the parasite as apparent from the distention and compression of illi and highly pronounced thinning of intestinal wall. Again, there was almost complete loss of normal architectural plan of the intestine besides congestion, compression, necrosis, thinning and shortening or atrophy of the villi (Figure-5). Other vital organs of the affected samples did not show any histopathological changes.

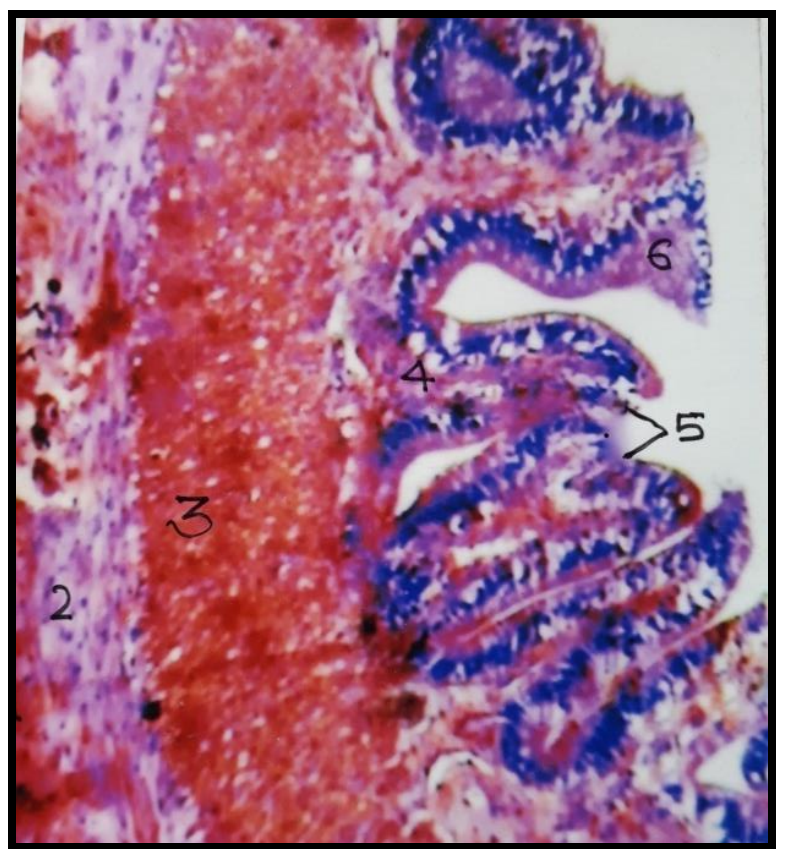

Fig 1: T. Section of intestine of normal Cyprinus carpio. H. \& E., X 150.

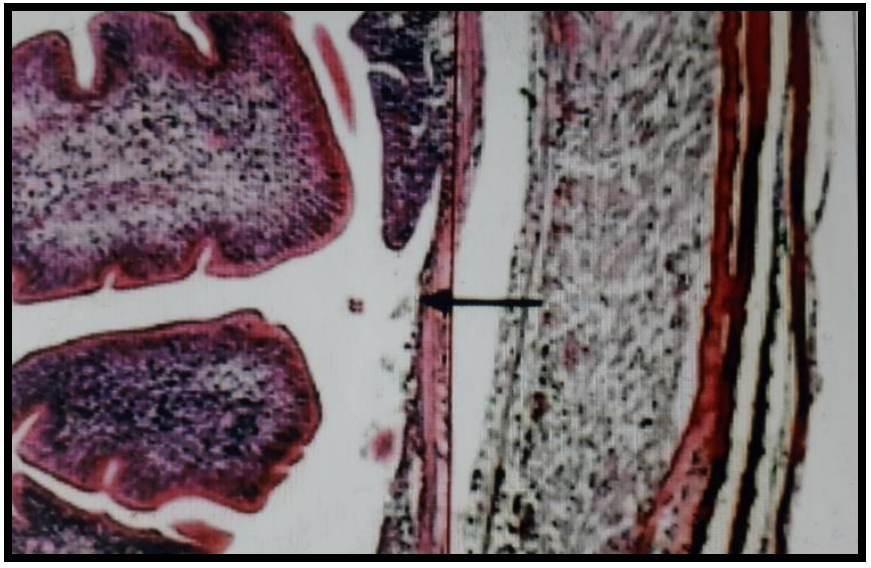

Fig 2: Due to infestation of B. acheilognathi in intestine of Cyprinus carpio showing $(\longrightarrow$ ) very high degree of intestinal compression with necrosis and complete loss of epithelium. H. \& E., X 150.

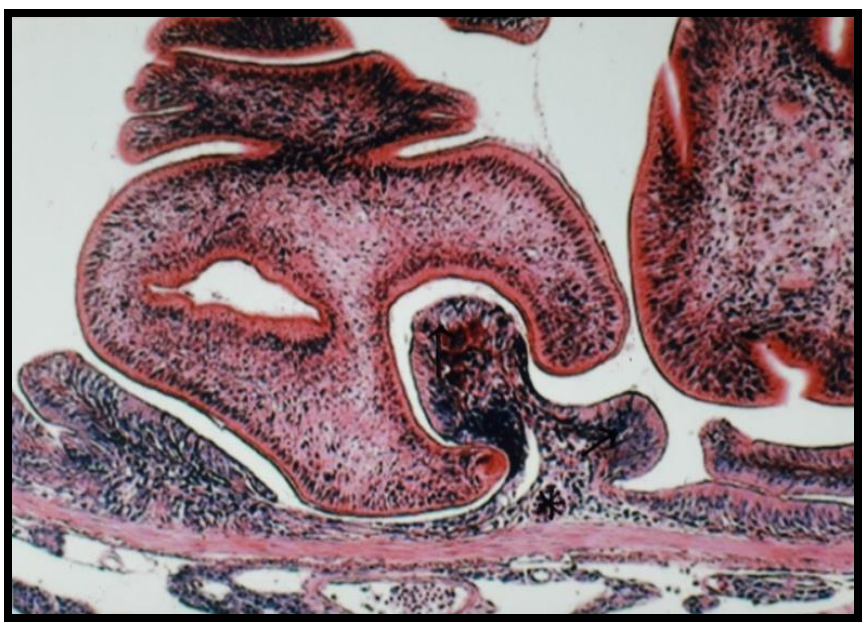

Fig 3: Due to engulfment of intestine by scolex of B. acheilognathi showing compression of mucosa $(\longrightarrow$ ) localized haemorrhage $(*)$. H. \& E., X 150 


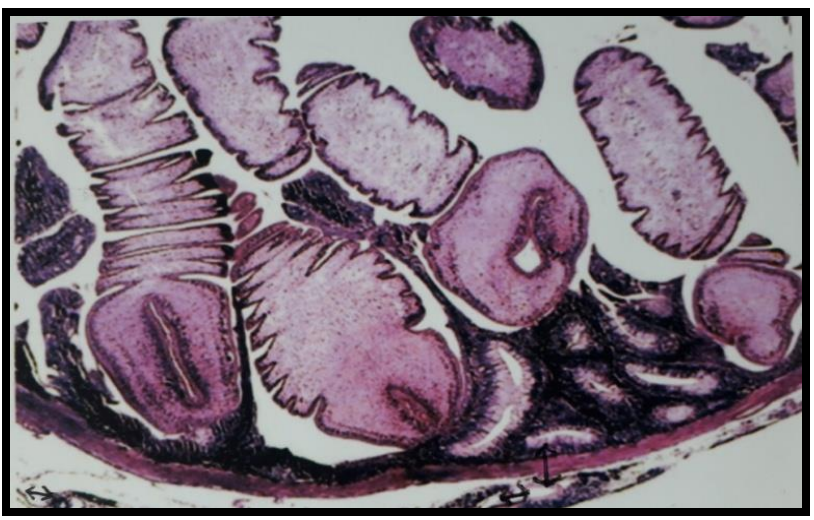

Fig 4: Cyprinus carpio intestine revealing thinning of intestine and pit formation $(\leftrightarrow$ ) in the intestinal wall caused by $B$. acheilognathi. H. \& E., X 150.

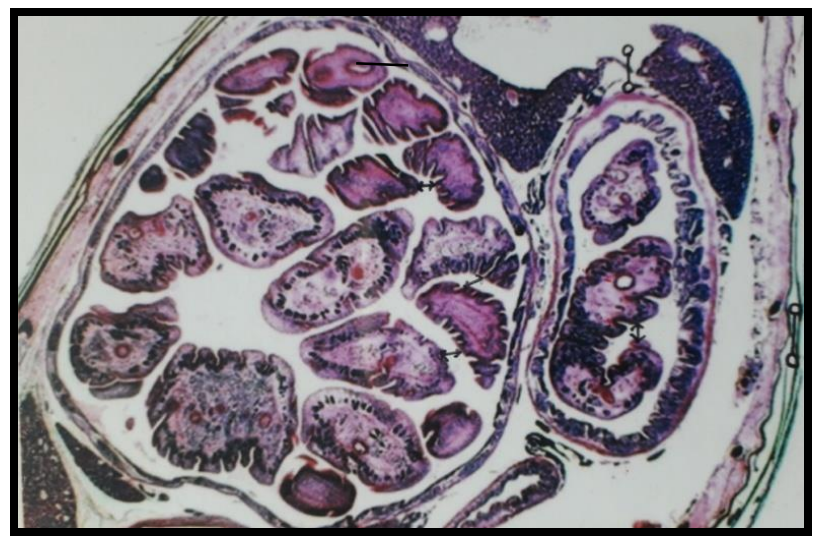

Fig 5: Due to infestation of B. acheilognathi induced loss of normal histo architecture of intestine of Cyprinus carpio showing ( highly compressed and atrophied illi and thinning of intestinal wall ( $)$. H. \& E., X 150.

\section{Discussion}

The present work, during the course of this study, identified the helminth parasite infecting the intestine of the common carp, Cyprinus carpio, as the cestode Bothriocephalus acheilognathi. The parasite could be identified upto species level easily by matching the morphological features as described by Yamaguti (1934) ${ }^{[14]}$ and Scholz et al. (2012) ${ }^{[10]}$. This parasite was first of all described in a cyprinid fish, Acheilognathus rhombeas, in Japan by Yamaguti (1934) [14] and subsequently spread in almost all parts of the world through trade and introduction in pisciculature (Heckmann, 2000) ${ }^{[4]}$. The severity of histopathological changes in the intestine of the common carp infected with the cestode, Bothriocephalus acheilognathi more or less similar observations have been noted earlier studies (Benerjee et al., 2007; Sinha et al. 1991; Kuchta 2018) ${ }^{[1,12,7]}$.

Sircar and Sinha (1980) ${ }^{[1]}$; Choudhary et al. (2015) ${ }^{[3]}$ also observed degenerative changes, such as hyperplasia and hypertrophy of intestinal villi, vacuolation in submucosal layer and proliferative changes leading to degeneration of various layers of the intestine infected with parasite. Similar findings were noted by Shostak and Dick (1986) ${ }^{[13]}$ and they have opined that circular infiltration and casting off of the epithelium are the characteristic lesions in response to parasitic infections and in chronic cases occurrence of fibrosis at the point of attachment also become visible.

\section{Conclusion}

The present finding concluded that infection of
Bothriocephalus acheilognathi in the common carp is a matter of concern as this parasite has the ability to adjust and multiply in new habitat/ region in diverse type of fishes. The significant histopathological changes includes hyperplasia and hypertrophy of intestinal villi, vacuolation in submucosal layer and proliferative changes leading to degeneration of various layers of the intestine infected with parasite.

\section{Acknowledgement}

The authors are thankful to the University Department of Zoology, LN Mithila University, Darbhanga, Bihar, India, for the provision of laboratory facilities used in this study.

\section{References}

1. Benarjee G, Reddy BL, Krishna Prasad KS, Srikanth K, Swamy M, Ramu G et al. Dynamics of parasite population and its histophysiological effects in the stomach of a freshwater fish. J Indian Fish. Assoc 2007;34:47-58.

2. Camargo MMP, Martinez CBR. Histopathology of gills, kidney and liver of a Neotropical fish caged in an urban stream. Neotrop. Inchthyol 2007;5:327-336.

3. Chaudhary A, Chiary HR, Bindu S, Singh HS. First molecular identification of invasive tapeworm, Bothriocephalus acheilognathi, Yamaguti, 1934 (Cestoda: Bothriocephalidea) in India 2015;4(4):269-276.

4. Heckmann RA. Asian tapeworm, Bothriocephalus acheilognathi, Yamaguti, 1934, a recent cestode introduction into the western United staes os America: Control methods and effect on endangered fish populations. Proc. Parasitol 2000;47:43-52.

5. Jha AN, Sinha P, Mishra TN. Seasonal occurrence of helminth parasites in fishes of Sikandarpur reservoir, Muzaffarpur (Bihar). Indian Journal of Helminthologu. 1992;44:1-8.

6. Luna G. Manual of histologic staining methods of the Amerd Forces Institute of Pathology, $3^{\text {rd }}$ Edition, McGrow -Hill Book Company, New York 1968.

7. Kuchta R, Choudhury A, Scholz T. Asian fish tapeworm: the most successful invasive parasite in freshwaters., 2018;34(6):511-523.

http://www.sciencedirect.com/science/journal/14714922 doi: 10.1016/j.pt.2018.03.001

8. Marcogliese DJ. Implications of climate change for parasitism of animals in the aquatic environment. Canadian Journal of Zoology 2001;79:1331-1352.

9. Ramudu KR, Dash G. Histopathological alteration in the vital organs of the Indian major carps with parasitic infestation in fish farms, West Bengal, India Durg Dev. Ther 2015;6:38-43.

10. Scholz T, Kuchta R, Williams C. Fish Parasites: Pathobiology and Protection (eds. Patrick, T.K. Woo and Kurt Buchmann). CAB International 2012, 282-297.

11. Sircar M, Sinha DP. Indian J Anim. Res 1980;14:53.

12. Sinha AK, Mehrotra PN. Pathogenicity of Bothriocephalus acheilognathi (Yamaguti) in the intestine of Xiphophorus helleri (Heckel). Rivista di Parassitologia 1991;8(2):181-185.

13. Shostak AW, Dick TA. Intestinal pathology in northern pike, Esox lucius L., infected with Triaenaphorus crassus Forel, 1868 (Cestode: psendophyllidea). Journal of Fish Diseases 1986;9:35-45.

14. Yamaguti S. Studies on the helminth fauna of Japan. Part 4. Cestodes of fishes. Japanese Journal of Zoology 1934;6(1):1-112. 